\title{
3D printing technology and its application in Nepalese context
}

\author{
Raj Kumar Chaulagain ${ }^{a, *}$, Saunak Niroula $^{a}$ \\ ${ }^{a}$ Department of Automobile and Mechanical Engineering, Thapathali Campus, Institute of Engineering, Tribhuvan University, Kathmandu,
} Nepal

\section{ARTICLE INFO}

\section{Article history:}

Received 29 Dec 2020

Received in revised form

$02 \mathrm{Feb} 2021$

Accepted 12 Feb 2021

Keywords:

3DP

Technology

Prototyping

Development

Manufacturing

\begin{abstract}
In context of digital manufacturing platform, Nepal is at an early stage of 3DP's application. The major objective of this research is to collect the application status of 3DP technology in Nepal. This paper presents a brief review of 3DP technology and case study conducted through survey on application of 3DP in Nepalese environment. The research showed presently professional and research based organization holds higher coverage among 40 different organizations spread over seven districts of the country. The major findings of the study is that the technology is in use since 2011 and was found increasing from 2015 only. Product examples of such application in Nepal were found more concerned to medical consumables and components of student research project.
\end{abstract}

\section{Abbreviations}

3D : Three dimensional

CNC : Computerized Numerical Control

CAD : Computer Aided Drawing

RP : Rapid prototyping

FDM : Fused Deposition Modeling

EBM : Electron Beam Melting

SLM : Selective Laser Melting

SHS : Selective Heat Sintering

SLA : Stereo Lithography Apparatus

DLP : Digital Light Processing

CLIP : Continuous Liquid Interface Production

LOM : Laminated Object Manufacturing

UV : Ultraviolet

*Corresponding author:

@rajkrc12@gmail.com (R.K. Chaulagain)
CJIEE Thapathali Campus, IOE, TU. All rights reserved

ASTM : American Society for Testing and Materials

USA : United States of America

MS : Micro-Soft

AM : Additive Manufacturing

MIT : Massachusetts Institute of Technology

FFF : Fused filament fabrication

\section{Introduction}

3DP is an example of an exciting technology being used to fabricate physical solid models for early verification of concepts, e.g., form, fit, and function as well as reducing lead-times for product development [1]. 3DP is also known as Additive Manufacturing, $\mathrm{AM}[2,3,4]$. It is a process in which a $3 \mathrm{D}$ physical model is printed from a digital design. It is fundamentally a different way of producing parts compared to traditional manufacturing technologies [5].

One of the key advantages of 3D printing is the ability to produce very complex shapes or geometries, and a prerequisite for producing any $3 \mathrm{D}$ printed part is a digital 3D model or a CAD file. There exists a large variety 
of 3D printers and technologies that needs to select for specific application and use a variety of materials, such as wax, plastics, metals and many more $[6,7]$.

The use of AM in each country can vary depending on the development of additive manufacturing in the country and also depends on the local needs of the country [8]. According to the report published by Grand View Research, Inc in February, 2020, North America accounted for the largest market share on the extensive adoption of 3D printers for 3D designing, modeling, and manufacturing in various industries. On the other hand, Asia Pacific has emerged as a manufacturing hub owing to an expanding consumer base as well as the continued rise in foreign investments [9].

Research on AM's use is still growing in various countries. More research on the use of AM and the impact of this use is still needed for future development [10]. In this context, application of 3DP in Nepal is still at an early stage and being used in different sector with multipurpose.

3DP technology has emerged during recent years as a flexible and powerful technique in various industry. Therefore, to create alertness of technology and collect the present scenario of its application in Nepal, this research has been conducted. This research covers the overview of 3DP technology, raw materials and field of application in general following different literatures. Various findings from the survey conducted through the questionnaire are discussed. This research is expected to be helpful for researchers, entrepreneurs and organizations those who are concerned of 3DP in Nepal.

\subsection{D printing technology and materials}

Charles Hull is the founder of 3DP-SLA in 1984 whereas Scott Crump is the founder of 3DP-FDM technology in 1989 [10]. Those were successful in making plastic and nylon parts. Dr. Carl Deckard and Dr. Joe Beaman developed SLS process at the University of Texas in the mid-1980s which was the only technology at that time to make prototyping parts in metals. In the early 1990s, the MIT invented inkjet 3D printing, known as 3DP. The 3DP revolution was started in 2005 with the open-source project called RepRap. Most 3D printers use FDM and SLA technology. They use opensource hardware and software to operate. With the advancement of computer technology and electronics and software, these 3D printers are the future [10].

There are varieties of 3D printing technologies developed with the different function. The basic processes involve Material Extrusion, Powder bed Fusion, Vat Photo-polymerization and Sheet Lamination [11]. The sub category under those processes are summarized in Table 1

The raw material which 3D printing processes may use to create $3 \mathrm{D}$ objects varies greatly from technology to technology. The material comes in the form of powders, filaments, liquids or sheets. While some material like thermoplastics can be melted and re-melted several times, others like thermosetting polymers cannot be melted back into a reusable liquid form as their internal composition changes once they are melted [19]. The major application area and possible raw materials used on different 3DP technology are listed on Table 2.

Application sector of 3DP is broad and can be categorized in various ways. According to Taufik M. et al. 2016, various kind of 3DP uses can be divided into three sectors: health, industrial, and sociocultural with different sub-sector of 3DP applications [20, 21].

\subsection{FDM based 3D printers}

FDM or FFF is a type of additive manufacturing that uses a continuous filament of a thermoplastic material and builds a part by heating and extruding this thermoplastic filament through a moving, heated extrusion print head one layer each time $[12,13]$.

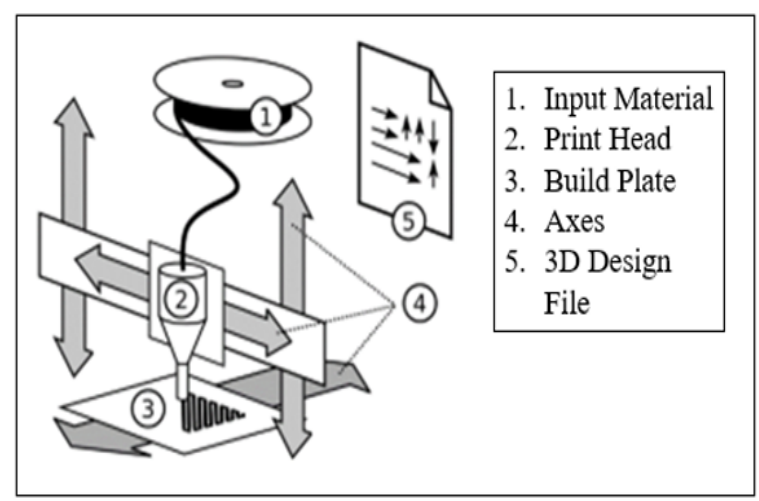

Figure 1: Common components of a FDM based 3DP [22]

In general, 3D printers have five common parts: input material, print head, build plate, axes, and 3D design file as shown in Figure 1. 3D-printed parts begin as input material in the form of solid filament which is deposited at the tip of the print head. It includes pushing filament through a metal extruder. The build plate is the base (flat surface) upon which the part is constructed. At the beginning of the $3 \mathrm{D}$ printing process, the print head is nearly touching the build plate. As more layers are added to the part, the distance between the print head and the build plate increases. The axes move the print head relative to the build plate. This enables the $3 \mathrm{D}$ 
3D printing technology and its application in Nepalese context

Table 1: Types of 3DP technology, Adapted from [11]

\begin{tabular}{|c|c|c|}
\hline Process & Technology & Technology Description \\
\hline $\begin{array}{l}\text { Material } \\
\text { Extrusion }\end{array}$ & FDM & $\begin{array}{l}\text { It uses a continuous filament of a thermoplastic material and } \\
\text { builds a part by heating and extruding this thermoplastic filament } \\
\text { through a moving, heated extrusion print head one layer each } \\
\text { time }[12,13] \text {. }\end{array}$ \\
\hline \multirow{5}{*}{$\begin{array}{l}\text { Powder bed } \\
\text { Fusion }\end{array}$} & 3DP & $\begin{array}{l}\text { A thin layer of the powder material is spread onto the fabrication } \\
\text { platform and an inkjet print head moves across the powder bed } \\
\text { depositing a liquid binding material that joins the powders [14]. }\end{array}$ \\
\hline & EBM & $\begin{array}{l}\text { It is based on a melting process which uses a metal powder and } \\
\text { an electron beam. The material is spread on the building platform } \\
\text { and heated by an electron beam [15]. }\end{array}$ \\
\hline & SLM & $\begin{array}{l}\text { Powdered material is spread over the fabrication bed and melted } \\
\text { or sintered by a high powdered optic laser. In this process the } \\
\text { metal material can be fully melted }[16,17] \text {. }\end{array}$ \\
\hline & SHS & $\begin{array}{l}\text { Material is fed from the powder deposition tanks, heated to just } \\
\text { below its melting point, spread out into a thin layer over the } \\
\text { movable building platform and flattened using a roller [14]. }\end{array}$ \\
\hline & SLS & $\begin{array}{l}\text { It uses a high power laser to sinter small parts of powdered } \\
\text { material aiming at specific points across a powder bed }[12,13] \text {. }\end{array}$ \\
\hline \multirow{3}{*}{$\begin{array}{l}\text { Vat Photo } \\
\text { Polymeriza- } \\
\text { tion }\end{array}$} & SLA & $\begin{array}{l}\text { It uses an ultraviolet (UV) laser which is focused on the top } \\
\text { surface of the resin which hardens precisely where the laser hits } \\
\text { its surface }[12,13] \text {. }\end{array}$ \\
\hline & DLP & $\begin{array}{l}\text { It uses a digital projector screen to flash a single image of each } \\
\text { layer across the entire platform at once }[12,13] \text {. }\end{array}$ \\
\hline & CLIP & $\begin{array}{l}\text { A beam of ultraviolet light is projected through an oxygen- } \\
\text { permeable window into the vat of liquid resin, illuminating the } \\
\text { precise cross-section of the object [18] }\end{array}$ \\
\hline $\begin{array}{l}\text { Sheet Lami- } \\
\text { nation }\end{array}$ & LOM & $\begin{array}{l}\text { A laminated sheet of material is spread through a roller mecha- } \\
\text { nism and computer controlled laser cuts the coated material to } \\
\text { form the desired shape of the object [12]. }\end{array}$ \\
\hline
\end{tabular}

Table 2: Raw materials and application of different technology [11, 12, 13, 14, 15, 16, 17, 18, 19]

\begin{tabular}{lll}
\hline Technology & Raw Materials & Application \\
\hline FDM & $\begin{array}{l}\text { Thermoplastic polymers, Ceramic slur- } \\
\text { ries, Metal pastes, Eutectic metals }\end{array}$ & $\begin{array}{l}\text { Prototyping, Biomedical, Toys, Ad- } \\
\text { vanced composite parts, Home use ap- } \\
\text { plications, Food technology, Buildings, } \\
\text { Construction }\end{array}$ \\
\hline 3DP, SLS, & $\begin{array}{l}\text { Polyamides, Polymer, Ceramic, Metal, } \\
\text { Glass powders, Thermoplastics, Nylon }\end{array}$ & $\begin{array}{l}\text { Biomedical , Electronics, Aerospace, } \\
\text { Lightweight structures, Heat exchangers }\end{array}$ \\
\hline \multirow{3}{*}{ SLA } & $\begin{array}{l}\text { Photopolymers, Ceramics, Semi-flexible } \\
\text { materials, ABS }\end{array}$ & $\begin{array}{l}\text { Biomedical, Excellent for form testing, } \\
\text { Best process for water resistant material, } \\
\text { Prototyping }\end{array}$ \\
\hline & Polymer composites, Ceramics, Paper \\
and metal filled tapes & $\begin{array}{l}\text { Paper manufacturing, Foundry indus- } \\
\text { tries, Electronics Biomedical, Ideal for } \\
\text { nonfunctional prototypes, Smart struc- } \\
\text { tures }\end{array}$ \\
\hline
\end{tabular}

printer to create a particular pattern for each new layer of material. The final part is made up of the patterns in each layer, stacked on top of each other. The 3D printing process is governed by a digital 3D design file. This file provides instructions to the $3 \mathrm{D}$ printer that describe how to move the axes, which in turn move the position of the print head relative to the build plate. The file controls exactly what patterns are produced in each layer; this determines which kind of part is produced by the $3 \mathrm{D}$ printer [22].

A typical 3D printing process starts with either a 3D scan of a real-world object, or with the creation of a digital representation of such object in a CAD soft-ware pack- 
age. The shape and other characteristics of the object are then stored in specialized file formats. After fixing potential errors in the digital representation of the object, specialized software transforms the representation into sliced instructions for a 3D printer, which then creates a three-dimensional reproduction of the original object. Once the actual printing is done, high-resolution postprocessing techniques are often applied, either compensating shortcomings of the $3 \mathrm{D}$ printing process or increasing the quality or resolution of the produced object. As there are no limitations in the digital representation of real-world objects, at least conceptually, nearly any shape or geometry can be reproduced with a 3D printer [23]. Emerging use of 3D printing technology is prevalent in automotive, manufacturing, aerospace, pharma $\&$ healthcare, fashion, retail and sports [24].

Mainly two types of 3d printer exist in the market; Desktop 3D printers and Industrial 3D printers [25]. Both desktop as well as industrial 3DP segment are further divided into hardware, software and services. The higher share of the industrial printer segment can be attributed to the extensive adoption in heavy industries, such as automotive, electronics, aerospace and defense, and healthcare. Prototyping, designing, and tooling are some of the most common industrial applications of the product type. The education sector, which comprises schools, educational institutes, and universities, is also deploying desktop printers for technical training and research purposes. Small businesses are particularly adopting desktop printers and are diversifying their business operations to offer $3 \mathrm{D}$ printing and other related services [26].

Most FDM systems allow the adjustment of several process parameters, including the temperature of both the nozzle and the build platform, the build speed, the layer height and the speed of the cooling fan. These are generally set by the operator, so they should be of little concern to the designer. From a designer's perspective, build size and layer height are major concerns. The typical layer height used in FDM varies between 50 and 400 microns. A smaller layer height produces smoother parts and captures curved geometries more accurately, while a larger height produces parts faster and at a lower cost. A layer height of 200 microns is most commonly used. The available build size of a desktop 3D printer is commonly $200 \times 200 \times 200 \mathrm{~mm}$, while for industrial machines this can be as big as $1000 \times 1000 \times 1000$ $\mathrm{mm}$. If a desktop machine is preferred (for example for reducing the cost) a big model can be broken into smaller parts and then assembled. [27].

\section{Research Methodology}

Presently, as the 3DP technology is highly emerging in Asian countries [8], there can be found the application of 3DP using in different sector and places over Nepal also. But there is a lack of compiled data base of the technological use by different organizations working on this sector. Therefore, the objective of this research has been focused to summarize the present scenario of 3DP in Nepalese environment through data analysis of collected data from survey.

A general methodology was adopted to conduct the research to fulfill the objective developed. Technological review was conducted and questionnaire was developed to collect the primary data. The collected data were tabulated, summarized in the form of graph using MSexcel and analyzed accordingly. Finally, the conclusions are presented on the basis of objective of this research.

\subsection{Limitations of the research}

This research was conducted within framework of the objective with the following limitations.

i Total numbers of concerned respondents identified was 40.

ii All the 3D printers mentioned are in working condition.

iii Analysis is based on the data of response.

iv Time frame of the data collection was from November, 2019 to April, 2020.

\subsection{Primary data collection from survey}

For this, questionnaire was prepared to have quick response from the 3DP concerned organizations. It was focused on working sector, year of involvement, model and quantity of 3DP unit available. The individuals or organizations even having a single 3DP unit were listed from all over Nepal to reach a maximum count as far as possible. The list was prepared with support of different personnel working in this field from different organizations of Nepal. For the collection of data from the respondents, different mediums of communication were used; field visit, e-mail, telephone and organizational website as well. Total 40 concerned organizations were listed from all over Nepal and followed for the response through feasible medium of conversation. All the questions weren't equally responded by all concerns so the analysis was conducted as per the data collected. Respondent chart summarizing the response for major questions is presented on Figure 2. 


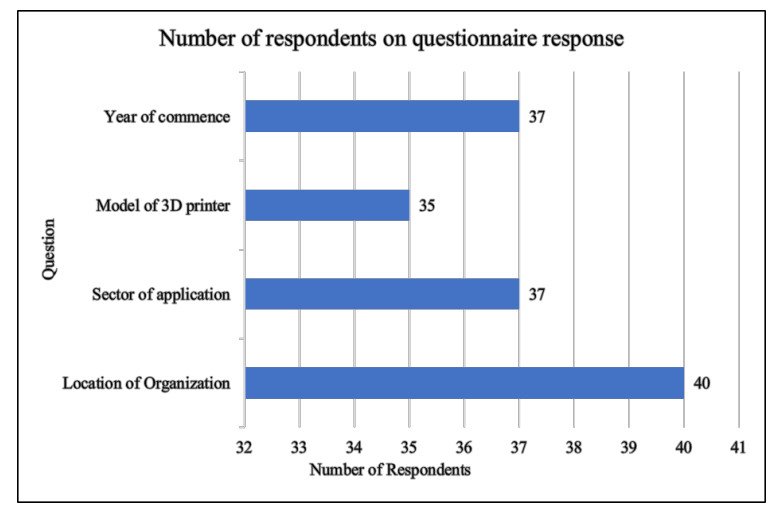

Figure 2: Number of respondent on questionnaire response

\section{Findings and discussion}

The data collected were compiled in the form of table with a comparative nature. Furthermore, the tabulated data were categorized on four different cluster and graph were plotted for the comparative summary in MS-excel.

The respondents selected were from all over Nepal which are located on different districts. The first cluster was termed as geography and was responded by all concerned. It was found that the organizations involving in 3DP technology are distributed on seven districts of Nepal being two inside the Kathmandu valley and rest outside the Kathmandu valley.

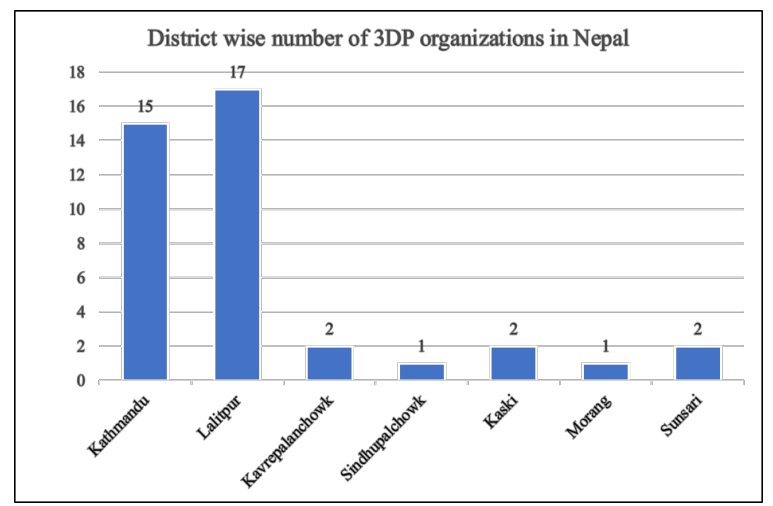

Figure 3: District wise number of 3DP organizations in Nepal till April 2020

The maximum number of organizations were found in Lalitpur district with the number 17 and minimum only one. The summary of the response regarding the district location of the organization is presented on Figure 3.

The second cluster was termed as focus area of organization working on 3DP. Out of 40 respondents, 37 replied their focus area of working with 3DP. From the data collected, those were categorized under health, professional, marketing, educational and student research as major involvement though other concerned are also performed. Here the category health includes the 3DP organization involving in medical equipment, prosthetics and humanitarian aid. Professional organization covers manufacturing of the commercial type of industrial products or any other prototypes whereas the marketing covers the supply of $3 \mathrm{D}$ printers.

Similarly, educational institutions covers the technological training of 3DP and category student research covers the organizations those are supporting the solid modeling activities of student based research.

From the data collected, it was found that both the professional and student research concerned organization holds the higher percentage of involvement as 30\% and $27 \%$ respectively. The involvement of rest of the organizations are also presented on the graph on Figure 4.

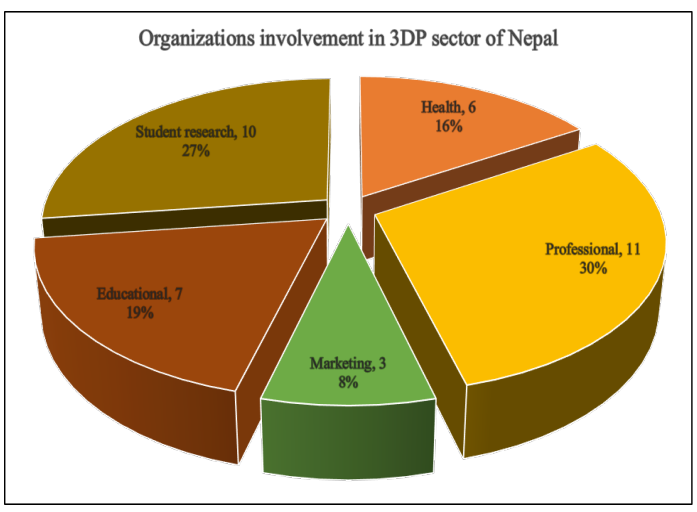

Figure 4: Application sector of 3DP technology in Nepal

An organization named Field Ready, have been found supporting the development of Nepal's 3D printing sector and assessing the value of 3D printing especially in rural and resource constricted environments. Varieties of products have been found on different sector of 3DP application. Some of them are listed as example in Table 3.

The third cluster was termed as 3D printer model that are available with different organizations working in Nepal. Out of 40 respondents, 35 mentioned the model of printers they are using on their area of application. The model of printers found were from diverse printer manufacturer and is listed in the Table 4. The 3D printers are all of desktop category and all are of FDM based expect Form 2 SLA printer and Formlabs Form 3B2020.

The fourth cluster was concentrated on the number of 
3D printing technology and its application in Nepalese context

Table 3: Few examples of application found in different 3DP sector of Nepal

\begin{tabular}{lll}
\hline S.No. & Application Sector & Few service/product examples found \\
\hline 1 & Health & $\begin{array}{l}\text { Hand/leg limbs, umbilical cord clamps, oxygen } \\
\text { supply fittings, medical consumables, EEG cap }\end{array}$ \\
\hline \multirow{2}{*}{ Professional } & $\begin{array}{l}\text { Electronic components, gear set, special pipe } \\
\text { fittings, teaching model set, architectural and } \\
\text { jewelry, topological model, molds for different } \\
\text { products, Legos, gift items, mask, face shield }\end{array}$ \\
\hline 3 & Marketing & Supply of 3D printers, filaments and components \\
\hline 5 & Educational & Demonstration, training, organizing workshop \\
\hline & Student research & $\begin{array}{l}\text { Wind/ water turbines, different working mech- } \\
\text { anisms, hand/leg limbs, 3D printed water filter, } \\
\text { drone parts, agricultural tool models }\end{array}$ \\
\hline
\end{tabular}

Table 4: Few examples of application found in different 3DP sector of Nepal

\begin{tabular}{ll}
\hline S.No. & 3D printer models found in Nepal \\
\hline 1 & Any cubic I3 Mega \\
2 & Assembled RepRapPro 3D printer \\
3 & Cetus 3D \\
4 & Creality (3040, CR 10, Ender 3/5) \\
5 & Creatbot Max \\
6 & Form 2 SLA 3D printer \\
7 & Formlabs Form 3B - 2020 (Bio 3D printer) \\
8 & Hictop Pursa I3 \\
9 & Inspire D290 \\
10 & Jenny Printer \\
11 & Printerbot metal PLUS \\
12 & Prusa \\
13 & TEVO Black Widow 3D printer \\
14 & TEVO Tarantula Dual Extruder \\
15 & TierTime \\
16 & UP (300, BOX Plus, mini 2, Plus 2) \\
17 & Winbo 3D printer \\
18 & IIIP \\
19 & Anet A8 3D printer \\
20 & K5 Plus Guru \\
\hline
\end{tabular}

3D printers available with different organizations on different running year. On this cluster, only 37 respondents mentioned the printer models over different years that they owned and commissioned. The data plotted shows the development scenario of 3DP technology over a time period of a decade.

It clears the use of 3DP system in Nepal was started from 2011 which was owned by Kathmandu University with a single unit. From 2015, the use of this technology was found increasing. Presently, the quantity of 3D printer comprising FDM and SLA based reached 64. Figure 5 shows an annual addition and cumulative number of 3D printers from 2011 to April 2020.

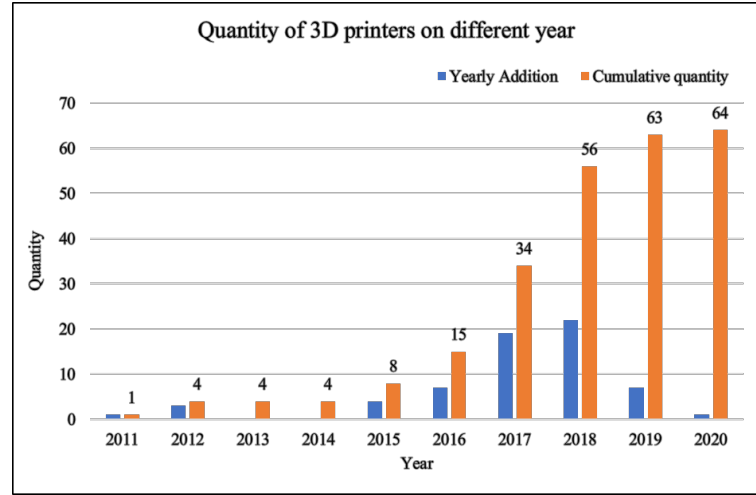

Figure 5: Quantity of 3D printers on different year

\section{Conclusion}

Adopting the suitable 3DP technology and raw materials for any type of application, the key benefits are shorter lead time, cost reduction, design freedom and re-making with optimum material utilization.

Based on research that has been conducted, the application of this technology is found spread over seven districts of Nepal increasingly widespread and covers areas including education, commercial manufacturing, health and various research activities. Among the organizations, professional and research based organizations has higher application coverage. The most types of machines owned by users were FDM based desktop with diverse printer models with the total quantity of 64 till the research period.

The use of this technology in Nepal is increasing in the last 5 years though it was found to be started from 2011. Various products were found and are more concerned to medical consumables and components made for student research project. It showed that the use of this technology can bridge the Nepalese manufacturing industry and academia with great future opportunity. 


\section{Acknowledgement}

This research has been conducted without any grant received from funding agencies in the public, commercial, or not-for-profit sectors. But great livelihood established during data collection from all the concerned 40 organizations and are highly acknowledged. Authors want to provide special thanks to Kathmandu University, National Innovation Center, Future lab, Field Ready, Innovative Ghar, Nepal Communitere, Robotic Association of Nepal and Pokhara University for their close support in shaping this research.

\section{References}

[1] Noorani R. Rapid Prototyping: Principles and Applications[M]. Englewood, NJ: John Wiley and Sons, 2006.

[2] Hod Lipson M K. Fabricated The New World of 3D Printing: number 1[M]. Wiley, 2013: 1-5.

[3] Gebhardt A. Understanding Additive Manufacturing: Rapid Prototyping - Rapid Tooling - Rapid Manufacturing[M/OL]. Cincinnati, USA: Hanser Publications, 2011: 591. http://www.sciencedirect.com/science/article/pii/ B9783446425521500021.

[4] Gibson I, Rosen D, Stucker B. Additive manufacturing technologies: 3D printing, rapid prototyping, and direct digital manufacturing, second edition[J/OL]. Additive Manufacturing Technologies: 3D Printing, Rapid Prototyping, and Direct Digital Manufacturing, Second Edition, 2015: 1-498. DOI: https://www.doi.org/10.1007/978-1-4939-2113-3.

[5] 3D Hubs. What is 3D printing? The definitive guide I 3D Hubs[EB/OL]. 2018[2020-05-06]. https://www.3dhubs.com/ guides/3d-printing/.

[6] Kianian B. 3D Printing and Additive Manufacturing State of the Industry, Annual Worldwide Progress Report: Chapters titles: The Middle East, and other countries[R]// Wohlers Report 3D Printing and Additive Manufacturing State of the Industry. Wohlers Associates, Inc., 2017.

[7] Noorani R. 3D printing: Technology, applications, and selection[M/OL]. Broken Sound Parkway NW: CRC Press, Taylor \& Francis Group, 2017: 1-271. DOI: https://www.doi.org/ $10.1201 / \mathrm{b} 21228$

[8] Gebler M, Schoot Uiterkamp A J, Visser C. A global sustainability perspective on 3D printing technologies[J/OL]. Energy Policy, 2014, 74(C): 158-167. DOI: https://www.doi.org/10.1016/ j.enpol.2014.08.033.

[9] Grand View Research. 3D Printing Market Growth \& Trends, 2020[EB/OL]. [2020-12-01]. https: //www.grandviewresearch.com/press-release/global-3dprinting-market.

[10] H. Khajavi S, Holmström J, Partanen J. Additive manufacturing in the spare parts supply chain: hub configuration and technology maturity[J/OL]. Rapid Prototyping Journal, 2018, 24(7): 1178-1192. DOI: https://www.doi.org/10.1108/RPJ-03-20170052.

[11] Ntousia M, Fudos I. 3D Printing Technologies and Applications: An Overview[C/OL]// Proceedings of CAD'19. 2019: 243-248. http://www.cad-conference.net. DOI: https://www.doi.org/ 10.14733/cadconfp.2019.243-248.

[12] Jasveer S, Jianbin X. Comparison of Different Types of 3D Printing Technologies[J/OL]. International Journal of Scientific and Research Publications (IJSRP), 2018, 8(4). http: //www.ijsrp.org/research-paper-0418.php?rp=P767298. DOI: http://dx.doi.org/10.29322/IJSRP.8.4.2018.p7602.

[13] Rengier F, Mehndiratta A, Von Tengg-Kobligk H, et al. 3D printing based on imaging data: Review of medical applications[J/OL]. International Journal of Computer Assisted Radiology and Surgery, 2010, 5(4): 335-341. DOI: https: //www.doi.org/10.1007/s11548-010-0476-x.

[14] Chia H N, Wu B M. Recent advances in 3D printing of biomaterials $[\mathrm{J} / \mathrm{OL}]$. Journal of Biological Engineering, 2015, 9(1): 4. http://www.jbioleng.org/content/9/1/4. DOI: http: //doi.org/10.1186/s13036-015-0001-4.

[15] Galati M, Iuliano L. A literature review of powder-based electron beam melting focusing on numerical simulations[J/OL]. Additive Manufacturing, 2018, 19: 1-20. DOI: https:// www.doi.org/10.1016/j.addma.2017.11.001.

[16] Sidambe A. Biocompatibility of Advanced Manufactured Titanium Implants-A Review[J/OL]. Materials, 2014, 7(12): 8168-8188. http://www.mdpi.com/1996-1944/7/12/8168. DOI: http://doi.org/10.3390/ma7128168.

[17] Spears T G, Gold S A. In-process sensing in selective laser melting (SLM) additive manufacturing[J/OL]. Integrating Materials and Manufacturing Innovation, 2016, 5(1): 16-40. http://link.springer.com/10.1186/s40192-016-0045-4. DOI: http://doi.org/10.1186/.

[18] Stansbury J W, Idacavage M J. 3D printing with polymers: Challenges among expanding options and opportunities[J/OL]. Dental Materials, 2016, 32(1): 54-64. DOI: https://www.doi.org/ 10.1016/j.dental.2015.09.018.

[19] Bechthold L, Fischer V, Hainzlmaier A, et al. 3D printing: A qualitative assessment of applications, recent trends and the technology's future potential[J/OL]. Studien zum deutschen Innovationssystem, 2015(17). https://ideas.repec.org/p/zbw/ efisdi/172015.html.

[20] Jain P, Taufik M. Additive Manufacturing: Current Scenario[C]// International Conference on: Advanced Production and Industrial Engineering. ICAPIE, 2016: 380-386.

[21] Ismianti, Herianto. Adoption of 3D Printing in Indonesia and Prediction of Its Application in 2025[J/OL]. IOP Conference Series: Materials Science and Engineering, 2020, 722 012028. https://iopscience.iop.org/article/10.1088/1757-899X/ 722/1/012028. DOI: https://www.doi.org/10.1088/1757-899X/ 722/1/012028.

[22] Anderson T. Anatomy of a 3D Printer: How Does a 3D Printer Work?[M/OL]// MatterHackers: number 39. 2016[2020-1203]. https://www.matterhackers.com/articles/anatomy-of-a-3dprinter.

[23] Bechtold S. 3D printing and the intellectual property system Economic Research Working Paper No. 28[EB/OL]. World Intellectual Property Organization, 2015: 28. https://www.wipo.int/publications/en/details.jsp?id= $3999\{$ Ź $\}$ plang $=\mathrm{EN}$.

[24] Pandian A, Belavek C. A review of recent trends and challenges in 3D printing $[\mathrm{C}] / /$ Proceedings of the 2016 ASEE North Central Section Conference. 2017: 1-17.

[25] Kodama H. Automatic method for fabricating a threedimensional plastic model with photo-hardening polymer[J/OL]. Review of Scientific Instruments, 1981, 52(11): 1770-1773. DOI: https://www.doi.org/10.1063/1.1136492.

[26] GVR. Global 3D Printing Market Size[EB/OL]. [202012-01]. https://www.printedelectronicsnow.com/contents/ view $\{$ _ breaking-news/2020-02-10/gvr-global-3d-printingmarket-size-was-1158-billion-in-2019.

[27] Bournias Varotsis A. Introduction to FDM 3D printing I 3D Hubs[M/OL]// 3D Hubs. 2020[2020-12-01]. https://www.3dhubs.com/knowledge-base/introduction-fdm3d-printing/. 